\title{
Solid Phase Extraction of Thorium on Multiwalled Carbon Nanotubes Prior to UV-Vis Spectrophotometric Determination in Ore Samples
}

\author{
Ghulam A. Kandhro, ${ }^{a, b, c}$, Mustafa Soylak*a, and Tasneem Gul Kazi ${ }^{\mathbf{b}}$ \\ ${ }^{a}$ Erciyes University, Fen Faculty, Department of Chemistry, 38039, Kayseri, Turkey \\ ${ }^{b}$ National Centre of Excellence in Analytical Chemistry, University of Sindh, Jamshoro, 76080, Pakistan \\ c Department of Basic Sciences, Mathematics and Humanities, \\ Dawood University of Engineering and Technology, Karachi, 74800, Pakistan
}

\section{INTRODUCTION}

Thorium is a characteristic element typically used in the field of nuclear energy. It is also used as the light source in gas mantles, for ceramic glazes, welding rods, thermistors, and catalysis. The intake of thorium occurs mainly through animal products, cereals, vegetables, and waters $(1,2)$. Thorium is a general health hazard and will persist long into the future as a component of residual radioactivity in the environment (1, 2-6).

Spectrophotometry is a simple and inexpensive alternative method for trace element determination due to its robustness and acceptable precision and accuracy, associated with lower cost in comparison with other techniques (613). However, direct determination of thorium by spectrophotometry is still difficult because of insufficient sensitivity, lack of selectivity, presence of a complex matrix, and poor precision and accuracy of the methods (14-17). However, these limitations can be solved by using separation and preconcentration techniques.

The preconcentration and separation steps improve the detection limits, increase sensitivity, and enhance the accuracy of the results (18-21). Solid phase extraction (SPE) is one of the most important preconcentration-separation procedures for trace heavy metal ions including thorium, due to its simplicity, low cost, selectivity, and minimum use of organic solvents

Corresponding autbor.

E-mail: soylak@erciyes.edu.tr

Tel E Fax: +90 3524374933

\section{ABSTRACT}

A separation-preconcentration method is presented for the solid phase extraction (SPE) of trace thorium(IV) as its arsenazo III complex in environmental samples on multi-walled carbon nanotubes (MWCNTs) by UV-Vis spectrophotometry. The influence of $\mathrm{pH}$ of the sample solutions, amount of arsenazo III, eluent type and volume, and sample volume were studied. The effects of the matrix ions were also examined. The detection limits (LOD) and quantification limits (LOQ) of 0.035 and 0.12 $\mu \mathrm{g} / \mathrm{L}$, respectively, were obtained. An enrichment factor of 40 was achieved for Th(IV) and the relative standard deviation was $<5 \%$. The presented method was applied for the determination of thorium in an ore sample with satisfactory results.

(22-25). Carbon nanotubes as an adsorbent for the preconcentration of trace heavy metals and organics are routinely used in solid phase extraction studies (22, 26-29)

In the present work, a simple, economic, and accurate solid phase extraction procedure using multi-walled carbon nanotubes (MWCNTs) for the spectrophotometric determination of traces of thorium using arsenazo III has been established. The analytical conditions, including $\mathrm{pH}$, amount of reagents, sample volume, eluent type, etc., were optimized. The matrix effects were also investigated.

\section{EXPERIMENTAL}

\section{Instrumentation}

Absorbances were measured using a Hitachi Model 150-20 UVVis double-beam spectrophotometer carrying a 10-mm optical path cell. For $\mathrm{pH}$ adjustments, a Nel $\mathrm{pH}-$ 900 glass electrode was used (Nel Instruments, Inc., Ankara, Turkey).

A glass column of $100 \mathrm{~mm}$ in length with an inner diameter of $10 \mathrm{~mm}$, equipped with porous frits, was filled up to a height of about $10 \mathrm{~mm}$ with a suspension of $100 \mathrm{mg}$ of multi-walled carbon nanotubes in water. Prior to use, the column was preconditioned with a phosphate buffer solution which was prepared in our laboratory.

\section{Reagents and Standard Solutions}

All chemicals were of analytical reagent grade. Distilled/deionized water was obtained with a Milli-Q ${ }^{\circledR}$ system, $18 \mathrm{M} \Omega \mathrm{cm}^{-1}$ resistivity, (Millipore Corporation, USA) was used for all experiments. Glassware and plasticware were cleaned by soaking in $10 \%(\mathrm{v} / \mathrm{v})$ nitric acid and rinsing with distilled water prior to use. Concentrated nitric acid $\left(\mathrm{HNO}_{3}\right.$, purity $\left.65 \%\right)$ and methanol were obtained from Merck (Darmstadt, Germany) and Sigma Aldrich (St. Louis, USA), respectively. Phosphate buffer solutions of $\mathrm{pH}$ 2.0-7.0 were used for $\mathrm{pH}$ adjustments.

Standard solutions of thorium were prepared by dilution of a certified standard solution $\left(1000 \mathrm{mg} \mathrm{L}^{-1}\right)$ obtained from High-Purity Standards Inc., Charleston, SC, USA. Working solutions were prepared 
by adequate dilution of the stock solution. Arsenazo III solution (3,6bis[(2- arsonophenyl)-azo)-4,5-dihydroxy-2,7-naphthalene-disulfonic acid) (Fluka Chemie, Buchs, Switzerland) was prepared by dissolving $0.1 \mathrm{~g}$ of the reagent in $100 \mathrm{~mL}$ distilled water.

\section{Preconcentration Procedure for $T h(V I)$}

A model solution containing 10-150 $\mu \mathrm{g}$ of Th(IV) was taken into a beaker and diluted to $50 \mathrm{~mL}$ with deionized water. The test solution, whose $\mathrm{pH}$ was already adjusted to 7.0 by using the phosphate buffer, was passed through the MWCNT column at a flow rate of $1.0 \mathrm{~mL} \mathrm{~min}^{-1}$. $10 \mathrm{~mL}$ of $1 \mathrm{M}$ nitric acid was used for the elution of Th(IV) retained in the column. The eluent was collected and arsenazo III added. For 10 minutes, the solution was left standing until the complete color development was finished, followed by measuring the absorbance spectrophotometrically at $659.4 \mathrm{~nm}$ against a blank (Figure 1).

\section{Digestion of Ore Sample}

The ore sample was collected from Sivas, Turkey, and placed in plastic bags. In the laboratory, the ore sample was oven-dried at $80^{\circ} \mathrm{C}$ and ground in a mortar to pass through a sieve to obtain a uniform particle size of 60 mesh. The sam- ple was then stored in a clean, dry, stoppered glass container.

An amount of $0.5 \mathrm{~g}$ of ore sample was weighed into a $100-\mathrm{mL}$ glass beaker that was acid-cleaned before use, $10 \mathrm{~mL}$ of $\mathrm{HNO}_{3}$ was added, followed by heating on a hot plate for 3 hours at $70^{\circ} \mathrm{C}$. Then, $5 \mathrm{~mL}$ of $\mathrm{HClO}_{4}$ was added; the temperature raised to $90{ }^{\circ} \mathrm{C}$, and left standing on the hot plate overnight. Further, $10 \mathrm{~mL} \mathrm{HNO}_{3}$ and $5 \mathrm{~mL} \mathrm{HClO}_{4}$ were added, and this mixture was heated for 24 hours at $70^{\circ} \mathrm{C}$ until a semi-dried mass was obtained. The residue was re-dissolved in $15 \mathrm{~mL}$ of $\mathrm{HNO}_{3}$ and $\mathrm{HCl}$ (1:1), and heated overnight at $70^{\circ} \mathrm{C}$. Finally, the residue was dissolved in $10 \mathrm{~mL}$ of $1 \mathrm{M} \mathrm{HNO}_{3}$ and diluted to the desired sample volume with deionized water. Then the preconcentration procedure given above was applied to this solution.

\section{RESULTS AND DISCUSSION}

\section{Effect of pH}

In the solid phase extraction of metal ions from various aqueous solutions, the $\mathrm{pH}$ of the working media is an important parameter for the quantitative recovery of the analytes on the adsorbent (30-33). The effect of $\mathrm{pH}$ on the adsorption of the Th(VI) ions on the MWCNTs

\section{Atomic Apectroscopy \\ $\bigcup$ Vol. 35(6), Nov./Dec. 2014}

was studied in the $\mathrm{pH}$ range of 2.0-7.0. The results in Figure 2 show that quantitative recoveries were obtained at the $\mathrm{pH}$ range of 4.0-5.0. Thus, $\mathrm{pH} 4.0$ was selected as the working $\mathrm{pH}$ for further studies.

\section{Effect of Reagent Concentration}

Thorium reacts with arsenazo III in a wide $\mathrm{pH}$ range $(\mathrm{pH} 4.0-7.0)$ to form a stable complex $(34,35)$. The influence of arsenazo III concentration on the absorbance of the complex was investigated by changing the volume of $0.1 \%$ concentration between $0.3-0.8 \mathrm{~mL}$. The results depicted in Figure 3 show that quantitative recoveries were obtained in the $0.5-0.8 \mathrm{~mL}$ range of $0.1 \%$ arsenazo-III. Therefore, $0.5 \mathrm{~mL}$ of $0.1 \%$ arsenazo III was used for all further experiments.

\section{Effect of Type and Volume of Eluent}

Based on our previous SPE studies of metal ions on carbon nanotubes (36-40), $10 \mathrm{~mL}$ of nitric acid at various concentrations was tested as the eluent for the retained Th(VI) on MWCNTs. The results listed in Table I show the quantitative recoveries obtained in the nitric acid concentration range of 1-3 M. For all further work, $10 \mathrm{~mL}$ of $1 \mathrm{M} \mathrm{HNO}_{3}$ was used as the eluent solution.

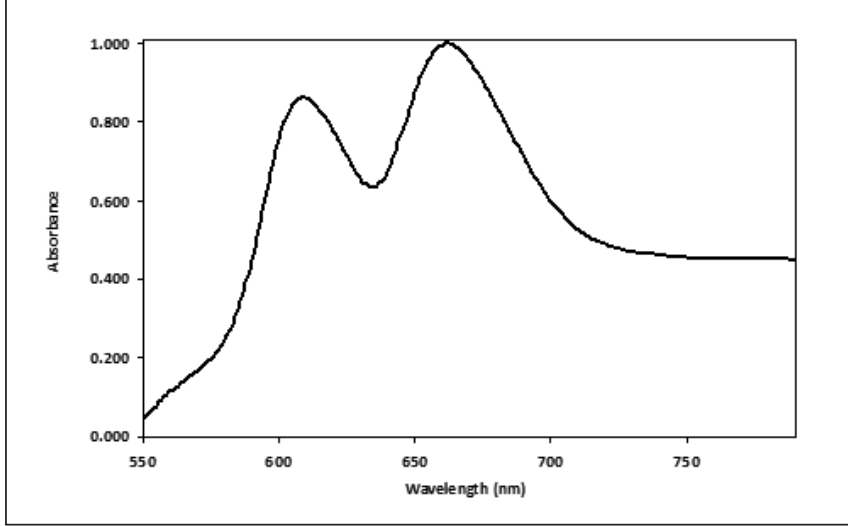

Fig. 1. UV-Vis spectrum of the thorium(IV)-arsenazo III complex $(\lambda$ max: $659.4 \mathrm{~nm})$.

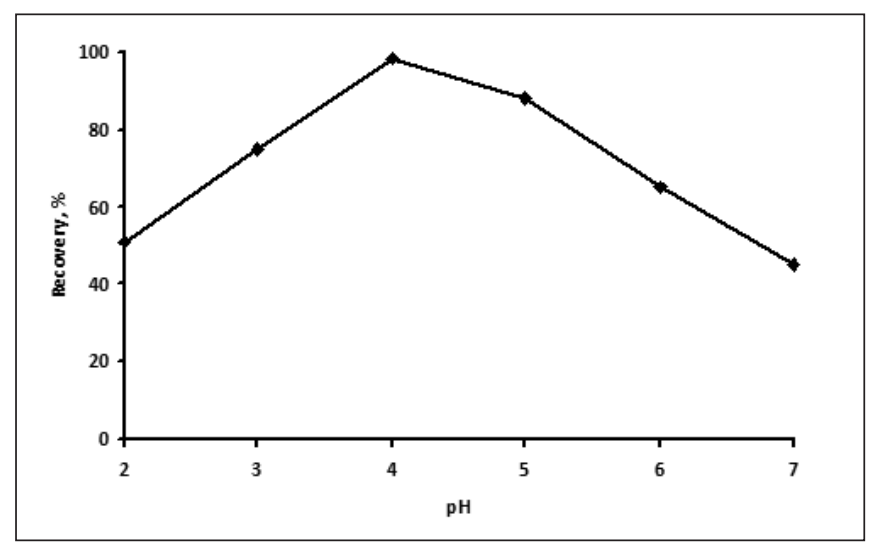

Fig. 2. Variation of $p H$ with recoveries of thorium (IV) $(N=3)$. 
TABLE I

Effect of Nitric Acid Concentration on the Recoveries of Th(IV) From MWCNTs ( $\mathrm{N}=3$ )

\begin{tabular}{cc}
\hline $\begin{array}{c}\text { Eluent Conc. } \\
(\mathrm{mL})\end{array}$ & $\begin{array}{c}\text { Recovery } \\
(\%)\end{array}$ \\
\hline 0.5 & 59.1 \\
1 & 98.5 \\
2 & 95.2 \\
3 & 95.2 \\
\hline
\end{tabular}

\section{Flow Rates of Sample and} Eluent

The effect of sample flow rate on the recovery values of $\mathrm{Th}(\mathrm{VI})$ was studied with sample solutions ranging from 1.0-10.0 mL/min (Figure 4). The recovery values were quantitative in the sample flow rate range of $1.0-5.0 \mathrm{~mL} / \mathrm{min}$. For further studies, the sample flow rate of $1.0 \mathrm{~mL} / \mathrm{min}$ was selected.

The effects of elution flow rates from 1.0 to $10.0 \mathrm{~mL} / \mathrm{min}$ were studied. The results in Figure 4 show that the recovery values were quantitative in the sample flow rate range of $1.0-4.0 \mathrm{~mL} / \mathrm{min}$. Thus, all further work was carried out using a $1.0 \mathrm{~mL} / \mathrm{min}$ flow rate for the eluent solutions.

\section{Effect of Sample Volume}

The influence of sample volume on the recovery of Th(IV) ions on the MWCNTs was investigated under optimum conditions in the sample volume range of $10-400 \mathrm{~mL}$ (Figure 5). Thorium(IV) ions were quantitatively recovered in all of the working ranges. The final volume of the solution was considered as $10 \mathrm{~mL}$ and a 40 -fold preconcentration factor was obtained.

\section{Effect of Diverse Ions on the Recovery of Thorium}

The influence of the diverse ions on the analyte signals in the spectroscopic determination is known as "matrix effects" (41-47). The effects of some metal ions on the recovery of Th(VI) was investigated. The results given in Table II show that a number of foreign ions $\left(\mathrm{Na}^{+}\right.$, $\mathrm{K}^{+}, \mathrm{Ca}^{2+}, \mathrm{Mg}^{2+}, \mathrm{Co}^{2+}, \mathrm{Ni}^{2+}, \mathrm{Mn}^{2+}$, and $\mathrm{Fe}^{3+}$ ) did not interfere in the proposed solid phase extraction system of Th(VI), even at higher concentrations, and that the recoveries were quantitative $(\geq 95 \%)$.

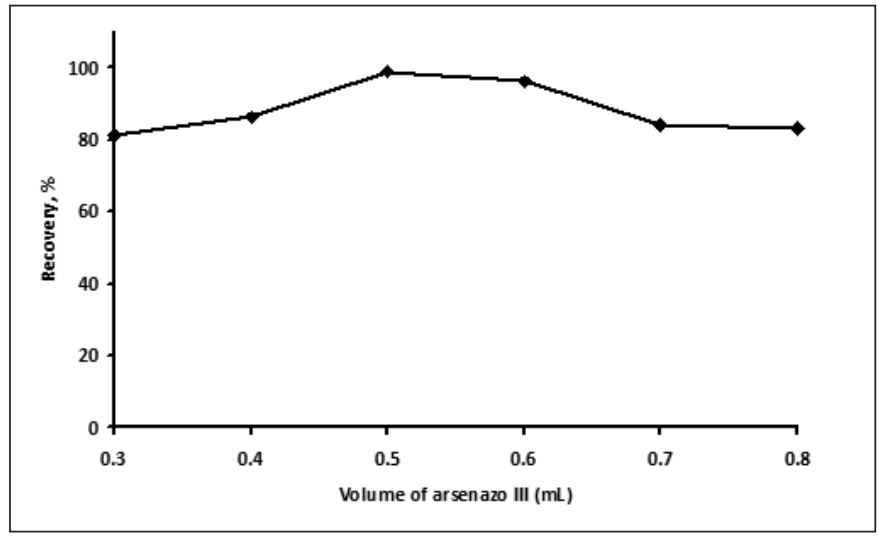

Fig. 3. Influence of volume of arsenazo III $(N=3)$.

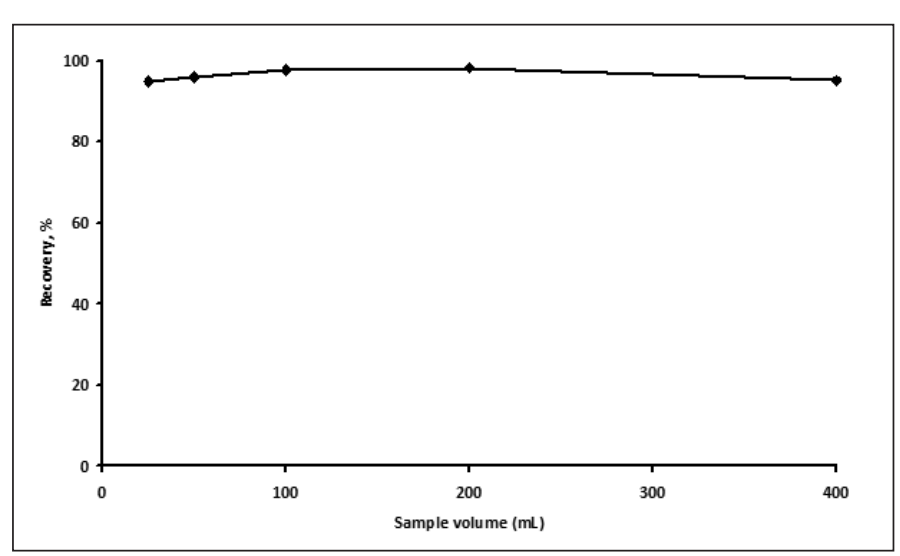

Fig. 5. Influence of sample volume in the proposed solid phase extraction system $(N=3)$.

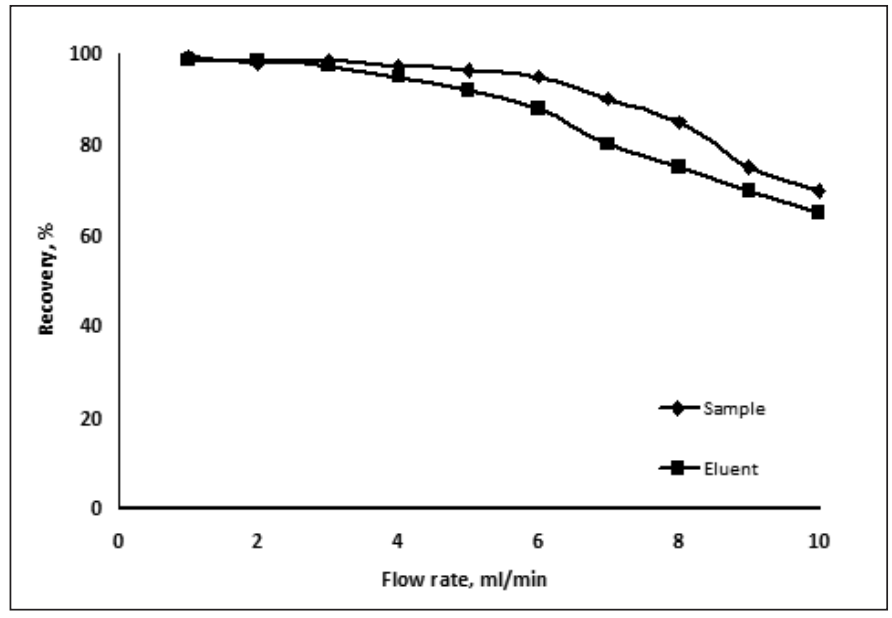

Fig. 4. Effect of sample and eluent flow rates $(N=3)$.

TABLE II

Tolerance Level of Matrix Ions on the Recoveries of Th(IV) in the Proposed System $(\mathrm{N}=3)$

\begin{tabular}{cccc}
\hline $\begin{array}{c}\text { Matrix } \\
\text { Ion }\end{array}$ & $\begin{array}{c}\text { Tolerance } \\
\text { Level }(\mathrm{mg} / \mathrm{L})\end{array}$ & $\begin{array}{c}\text { Matrix } \\
\text { Ion }\end{array}$ & $\begin{array}{c}\text { Tolerance } \\
\text { Level }(\mathrm{mg} / \mathrm{L})\end{array}$ \\
\hline $\mathrm{Na}^{+}$ & 1500 & $\mathrm{Mn}^{2+}$ & 20 \\
$\mathrm{~K}^{+}$ & 1500 & $\mathrm{Fe}^{3+}$ & 15 \\
$\mathrm{Ca}^{2+}$ & 1000 & $\mathrm{Zn}^{2+}$ & 20 \\
$\mathrm{Mg}^{2+}$ & 1000 & $\mathrm{Cd}^{2+}$ & 20 \\
$\mathrm{Co}^{2+}$ & 20 & $\mathrm{Cu}^{2+}$ & 20 \\
$\mathrm{Ni}^{2+}$ & 20 & $\mathrm{~Pb}^{2+}$ & 20 \\
\hline
\end{tabular}




\section{Analytical Features of the Proposed Method}

The analytical characteristic data of the proposed method were achieved under the optimum experimental parameters. The calibration curve (Figure 6) was obtained in the $0.125-5.0 \mathrm{mg} \mathrm{L}^{-1}$ range, with a correlation coefficient $\left(R^{2}\right)$ of 0.9979 . The regression equation was $\mathrm{A}=0.0193 \mathrm{C}+0.0018$ ). The limit of detection, calculated as the concentration of the absolute amount of analyte yielding a signal equivalent to three times the standard deviation of the blank signal $(\mathrm{n}=10)$, was $0.035 \mu \mathrm{g} \mathrm{L}^{-1}$. The quantification limit (LOQ) was $0.12 \mu \mathrm{g} \mathrm{L}^{-1}$. The relative standard deviation (RSD) for 10 replicate measurements of $0.125 \mathrm{mg} \mathrm{L}^{-1}$ of Th(VI) was $<5.0$. Thus, it can be seen that the present procedure is applicable to real samples with low LOD, LOQ, and RSD values.

\section{Application}

The proposed procedure was applied to the determination of the thorium content in an ore sample from Sivas City, Turkey. An additional recovery test was applied to this sample and then the preconcentration procedure was applied. The results given in Table III show that the recoveries of thorium were quantitative.

\section{CONCLUSION}

The results suggest that multiwalled carbon nanotubes (MWCNTs) can be used as a reliable preconcentration method for the solid phase extraction of Th(IV) with arsenazo III as the chromophore. The limit of detection and the limit of quantification were $0.035 \mu \mathrm{g} \mathrm{L}^{-1}$ and $0.12 \mu \mathrm{g} \mathrm{L}^{-1}$, respectively. The preconcentration factor obtained was 40 . The preconcentration-separation method was applied for the determination of thorium levels in ore sample with acceptable results. The quantitative recoveries were $<95 \%$, with a relative standard deviation lower than $5 \%$.

TABLE III

Application of Proposed SPE of Th(IV) From Ore Sample (Sivas, Turkey) $(\mathrm{N}=4)$

\begin{tabular}{ccc}
\hline $\begin{array}{c}\text { Added } \\
\left(\mu \mathrm{g} \mathrm{g}^{-1}\right)\end{array}$ & $\begin{array}{c}\text { Observed } \\
\left(\mu \mathrm{g} \mathrm{g}^{-1}\right)\end{array}$ & $\begin{array}{c}\text { Recovery } \\
(\%)\end{array}$ \\
\hline 0 & $10.0 \pm 0.8$ & - \\
100 & $109 \pm 8.0$ & 99.0 \\
200 & $206 \pm 7.0$ & 98.0 \\
400 & $402 \pm 9.0$ & 98.0 \\
\hline
\end{tabular}

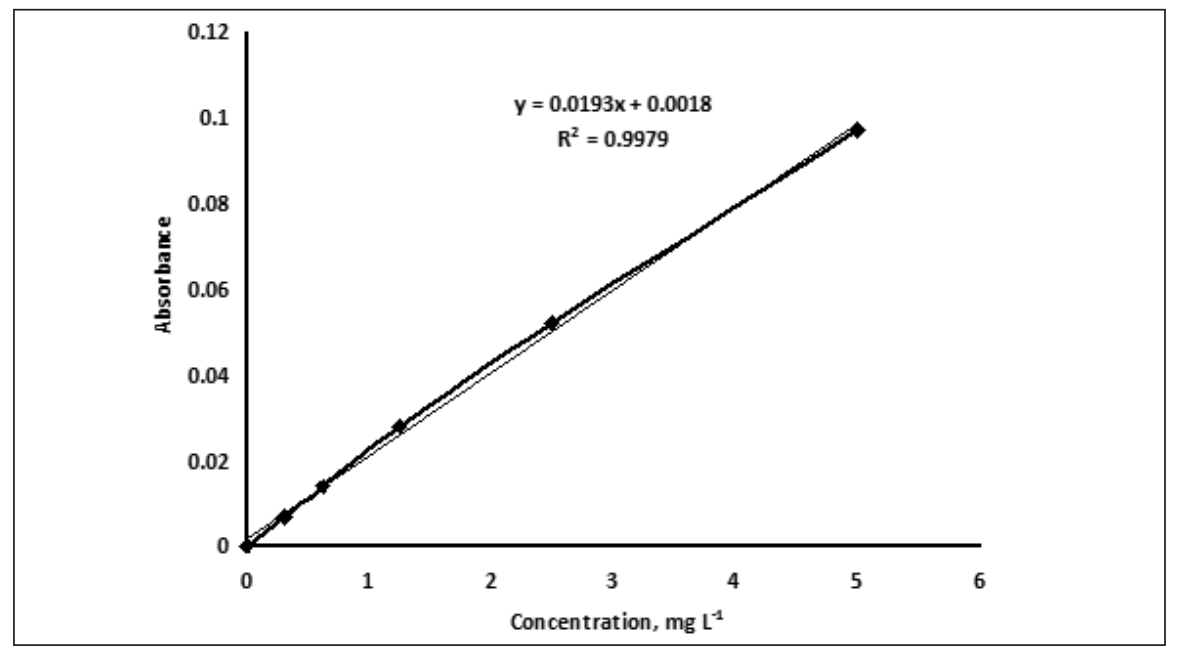

Fig. 6. Calibration curve for thorium(IV).

\section{Atomic Apectroscopy \\ 1 Vol. 35(6), Nov./Dec. 2014}

\section{ACKNOWLEDGMENT}

Dr. G.A. Khandro thanks the Scientific and Technological Research Council of Turkey (TUBITAK) for participation in the " 2216 Research Fellowship Programme for Foreign Citizens" and the financial support. The authors also thank Mr. Erkan Yilmaz and Mr. Yunus Emre Unsal for their help.

Received April 23, 2014. 